\title{
EFFECT OF DIFFERENT NON-INVASIVE AND MICRO-INVASIVE TREATMENT MODALITIES OF WHITE SPOT LESIONS ON MICROHARDNESS OF HUMAN ENAMEL
}

\author{
Hend S. Ahmed *
}

\begin{abstract}
Aim: to investigate effect of different treatment modalities of white spot lesions on microhardness of human enamel.

Materials and methods: twenty-four recently extracted sound human maxillary incisor teeth were collected. Teeth were divided randomly into six groups (10 each) that were summarized as follows: Group 1: sound unprepared teeth (base line control); Groups 2: demineralized enamel (negative control), Group 3: Demineralized enamel treated by resin infiltration (ICON), Group 4: demineralized enamel treated by bioactive glass (Sylc powder) as remineralizing agent, Group 5: demineralized enamel treated by fluoride varnish ( positive control), Group 6: Demineralized enamel treated by microabrasion. Teeth were fixed in the acrylic blocks with their labial surface flushed with the flat surface of the mold. All specimens except the base line control specimens were demineralized. Each group was treated with the assigned treatment according to manufacturer's recommendations. The microhardness measurements were performed using a Vickers Microhardness Tester with a Vickers diamond indenter and a 20X objective lens.
\end{abstract}

Results: showed that there was a statistically significant difference in $\mathrm{MH}$ values between different study groups $(\mathrm{P}<0.001)$. The significantly highest $\mathrm{MH}$ mean values were recorded in (microabrasion), (sound enamel), (resin infiltration), and (Sylc powder) groups, which did not differ significantly. This was followed by the mean value of (fluoride varnish) group. While (demineralized enamel) group yielded significantly lowest MH values.

Conclusions: among the tested treatment modalities, microabrasion, resin infiltrant as well as bioactive glass air abrasion improved enamel surface microhardness in comparison to fluoride varnish.

KEYWORDS: white spot lesions, microhardness, non-invasive treatment, micro- invasive treatment

\footnotetext{
* Lecturer of Restorative Dentistry, Faculty of Dentistry, The British University in Egypt.
} 


\section{INTRODUCTION}

Dental caries is one of the prevailing chronic diseases, that is recently considered as a reversible disease. It consists of two processes, demineralization and remineralization. It is reversable in its early stages but after cavitation it is considered irreversible and destructive ${ }^{(1)}$.

Recently, the methods used to control dental caries had changed radically from the regular traditional restorative methods to the recent preventive, non- invasive and minimally invasive methods ${ }^{(2)}$.

New conservative and minimally invasive approaches have been tracked to treat non cavitated lesions at their early stages ${ }^{(2)}$

White spot lesions are considered the earliest macroscopic evidence of dental caries ${ }^{(1)}$. White spot lesions occur when the organic acids produced by the pathogenic bacteria have leached out a certain amount of calcium and phosphate ions. These ions may or may not be compensated by the natural remineralization process. Therefore, porosities that created on the enamel surface will change the refractive index (RI) of enamel which is usually translucent and therefore white spot lesions start to compromise esthetics as it starts to appear macroscopically ${ }^{(3)}$.

Various conservative methods were introduced to heal these defects. One of the non-invasive methods of treatment of white spot lesions is the remineralization using fluoride varnish. According to many studies, the anti-carious activity of the fluoride varnish is related to its fluoride release as it promotes the remineralization of enamel, prevents its demineralization and increases the enamel hardness ${ }^{(4,5)}$.

Another conservative method used in the treatment of hypo-mineralized enamel is the resin infiltration method, which is considered a microinvasive method of treatment of the white spot lesions ${ }^{(6)}$. Since 2009 , a resin material with a low viscosity and a high penetration coefficient has been developed and named Icon caries infiltrant ${ }^{(7)}$. This resin infiltration method includes filling up the subsurface lesion porosities with the resin infiltrant. The enamel surface is first conditioned with a strong acid. By the capillary forces, The infiltrants are capable of penetrating the porous structure of lesion ${ }^{(8,9)}$, so the porosities of the carious lesion are closed and the loss of minerals is stopped ${ }^{(6)}$. Treatment of white spot lesions using this micro invasive method shown to significantly arrest enamel lesions and reduce mineral loss ${ }^{(10)}$.

Microabrasion is also used as a microinvasive method of treatment of white spot lesions ${ }^{(11)}$. This technique has been used since 1986 in combination with tooth bleaching techniques ${ }^{(12)}$. It involves multiple applications of an acidic and abrasive compounds to the demineralized enamel surface to remove the outermost surface layer exposing new enamel surface with highly smooth and polished texture ${ }^{(11)}$.

More recently, Sylc has been used in remineralizing the incipient carious lesions. Sylc is a therapeutic powder composed of $100 \%$ Novamin bioactive glass which endures a rapid reaction on the surface and form hydroxycarbonate apatite (HCA) when exposed to an aqueous environment. HCA is considered chemically similar to natural tooth minerals ${ }^{(13)}$.

Micro hardness testing is considered a simple and a reliable method to obtain indirect information on mineral content changes in dental hard tissues $^{(14)}$

So the aim of this study was to investigate effect of different non-invasive and micro-invasive treatment modalities of white spot lesions on microhardness of human enamel. The null hypothesis of this study was that the various treatment modalities of white spot lesions would not significantly affect the microhardness of human enamel. 


\section{MATERIALS AND METHODS}

\section{Sample size calculation}

Sample size calculation was conducted using G*Power 3.1.9.4 Software based on data obtained from a previous study (Zhao and Ren, 2016) which reported a mean difference in microhardness of $102.7 \pm 18.1 \mathrm{~kg} / \mathrm{mm}^{2}$ between sound enamel and resin-infiltrated enamel lesions. The power of t-test was set at $95 \%$ using a two-tailed significance level of 5\% and an effect size of 3.66. A sample size of 4 human incisors per group was estimated, for a total of 24 incisors per 6 groups.

\section{Teeth selection}

In this in vitro study, twenty four recently extracted sound human maxillary incisor teeth free from caries, hypoplastic defects, fracture or cracks were collected. Teeth were stored in saline solution containing $0.1 \%$ thymol at $4^{\circ} \mathrm{C}$ until used.

\section{Teeth grouping}

Teeth were divided at random into six groups (10 each) that were summarized as follows:

Group 1: Sound unprepared teeth (base line control);

Group 2: Demineralized enamel (negative control).

Group 3: Demineralized enamel treated by resin infiltration (ICON)

Group 4: Demineralized enamel treated by bioactive glass (Sylc powder) as remineralizing agent.

Group 5: Demineralized enamel treated by fluoride varnish ( positive control).

Group 6: Demineralized enamel treated by microabrasion

\section{Specimen preparation}

Each incisor was imbedded in rectangular transparent auto-polymerized acrylic resin block (Acrostone, Egypt). The block dimensions were $(2.5 \mathrm{~cm} 2.0 \mathrm{~cm} 1.5 \mathrm{~cm})$. Split mold assembly was used for pouring six blocks simultaneously. Each tooth was fixed in the acrylic while it was in soft and the tooth was pressed till its flat part of the labial surface was flushed with the flat surface of the mold. After hardening of the acrylic, the block was removed and checked accurately.

\section{Demineralization phase of teeth}

All the specimens except the base line control specimens were demineralized by suspending all the teeth into glass tubes containing $20 \mathrm{ml}$ of demineralizing solution $\left(\mathrm{CaCl}_{2}=2.2 \mathrm{mM}, \mathrm{Na} \mathrm{H}_{2} \mathrm{PO}_{4}\right.$ $=2.2 \mathrm{mM}$, Lactic acid $=0.05 \mathrm{M}$, Fluoride $=0.2 \mathrm{ppm}$, solution was adjusted with $50 \% \mathrm{Na} \mathrm{OH}$ to $4.5 \mathrm{pH}$ ). The specimens were stored for 72 hours, in an incubator at a temperature of $37^{\circ} \mathrm{C}{ }^{(15)}$.

\section{Treatment of the demineralized lesions}

All the specimens except the negative and positive control specimens were treated according to the assigned groups as follows;

\section{Group 3}

Demineralized enamel treated by resin infiltration (ICON; DMG, Hamburg, Germany). The procedure was done in accordance to the manufacturer's recommendations: (1) Icon-Etch (15\% hydrochloric acid) was placed for 2 minutes followed by rinsing with water and drying by air for 30 seconds; (2) Icon-Dry (ethanol) was placed for 30 seconds and dried by air; (3) Icon-Infiltrant was placed twice, first application for 3 minute and second application for 1 minute; (4) both infiltrant layers were cured for forty seconds by a LED unit (Elipar S10, 3M ESPE, St Paul, MN, USA) with light intensity $1200 \mathrm{~mW} / \mathrm{cm}^{2}$ in accordance to manufacturer recommendations.; (5) polishing of specimens were done using aluminum oxide discs (4000 grit; FEPA-P, Extec) for twenty seconds removing the excess material.

\section{Group 4:}

The demineralized specimens were treated with Bioactive glass 45S5 Sylc powder (Sylc; Denfotex 
Research Ltd) with particle size $=38-90 \mu \mathrm{m}^{(16)}$. This powder is composed of $100 \%$ Novamine bioactive glass; calcium sodium phosphor-silicate. The bioactive glass powder was applied in accordance to the manufacturer recommendations, it was applied using NSK Prophymate Neo handpiece with air stream adjusted at 40-46 psi. The distance between the handpiece and the specimens was constant about (3-4mm) with 60-80 degrees on the buccal surfaces. The powder application was for 5-10 seconds per specimen in a circular movement.

\section{Group 5:}

The demineralized specimens were treated with fluoride varnish (Bifluorid 10 by VOCO, Germany). It is a rapid- drying suspension of equal amounts of sodium fluoride and calcium fluoride. Thin coat was placed on labial surface and left for 10-20 seconds then air dried. The single dose form was used, to standardize the amount of fluoride varnish applied per specimen. Then specimens were stored in artificial saliva $\left(1.5 \mathrm{mM} / 1 \mathrm{CaCl}_{2}, 50 \mathrm{mM} / 1 \mathrm{KCl}\right.$, $0.9 \mathrm{mM} / 1 \mathrm{KH}_{2} \mathrm{PO}_{4}$, and adjusted $\mathrm{pH}=7.4$ ) for fourteen days in an incubator at a temperature of $37^{\circ} \mathrm{C}$ and the artificial saliva was changed every 24 hours.

\section{Group 6:}

The demineralized specimens were treated with microabrasion slurry (MA; Opalustre, Ultradent, South Jordan, UT, USA). The slurry composed of $6.6 \%$ hydrochloric acid and silicon carbide microparticles (20-160 mm). The slury was applied to enamel defects using rubber cups mounted in a low- speed handpiece for a period of 60 seconds at periods of 30 sseconds.

\section{Microhardness Testing}

The microhardness measurements were performed using a Vickers Microhardness Tester (Model HVS-50, Laizhou Huayin Testing Instrument Co., Ltd. China) with a Vickers diamond indenter and a $20 \mathrm{X}$ objective lens. The microhardness measurements were taken at three different points for each sample. The indentations were made approximately $0.5 \mathrm{~mm}$ from each other. Each measurement was carried out by using a $200-\mathrm{g}$ load for $15 \mathrm{~s}$, oriented perpendicularly to the buccal surface. The diagonal lengths of indentations were measured by built in scaled micrometer and measurements were converted into Vicker's numbers. The values were averaged to produce one hardness value for each sample.

\section{Micro-hardness calculation}

Micro-hardness was obtained using the following equation:

\section{$H V=1.854 P / d^{2}$}

where,

$\mathbf{H V}$ is Vickers hardness in $\mathrm{Kgf} / \mathrm{mm}^{2}$,

$\mathbf{P}$ is the load in Kgf and

d is the average length of the diagonals in $\mathrm{mm}$

\section{Statistical analysis}

Statistical analysis was done with IBM SPSS Statistics Version 20. Data was presented as mean and standard deviation (SD). Significance level was set at $\mathrm{P}=0.05$. Kolmogorov-Smirnov and ShapiroWilk tests were used to assess data normality. OneWay ANOVA and Tukey's HSD post-hoc test were conducted to compare microhardness $(\mathrm{MH})$ values between different study groups.

\section{RESULTS}

One-Way ANOVA followed by Tukey's HSD post-hoc test (Table 1) showed that there was a statistically significant difference in $\mathrm{MH}$ values between different study groups $(\mathrm{P}<0.001)$. The significantly highest $\mathrm{MH}$ mean values were recorded in (demineralized enamel + microabrasion), (sound enamel), (demineralized enamel + resin infiltration), and (demineralized enamel + Sylc powder) groups, which did not differ significantly. This was followed by the mean value of (demineralized enamel + fluoride varnish) group. While (demineralized enamel) group yielded the significantly lowest $\mathrm{MH}$ values among the other study groups. 
TABLE (1): Mean \pm SD for the effect of different treatment modalities of white spot lesions on microhardness $(\mathrm{kg} / \mathrm{mm} 2)$ of enamel.

\begin{tabular}{|c|c|}
\hline & Microhardness \\
\hline Sound enamel & $283.28 \pm 9.67^{\mathrm{a}}$ \\
\hline Demineralized enamel & $160.49 \pm 3.09^{\mathrm{c}}$ \\
\hline Demineralized enamel + Resin infiltration & $282.71 \pm 6.99^{\mathrm{a}}$ \\
\hline Demineralized enamel + Sylc powder & $271.65 \pm 8.14^{\mathrm{a}}$ \\
\hline Demineralized enamel + Fluoride varnish & $248.73 \pm 14.92^{\mathrm{b}}$ \\
\hline Demineralized enamel + Microabrasion & $285.15 \pm 7.90^{\mathrm{a}}$ \\
\hline P-value & $<0.001^{*}$ \\
\hline
\end{tabular}

*: significant at $P \leq 0.05$

Means with different superscript letters are statistically significant different at $P<0.05$

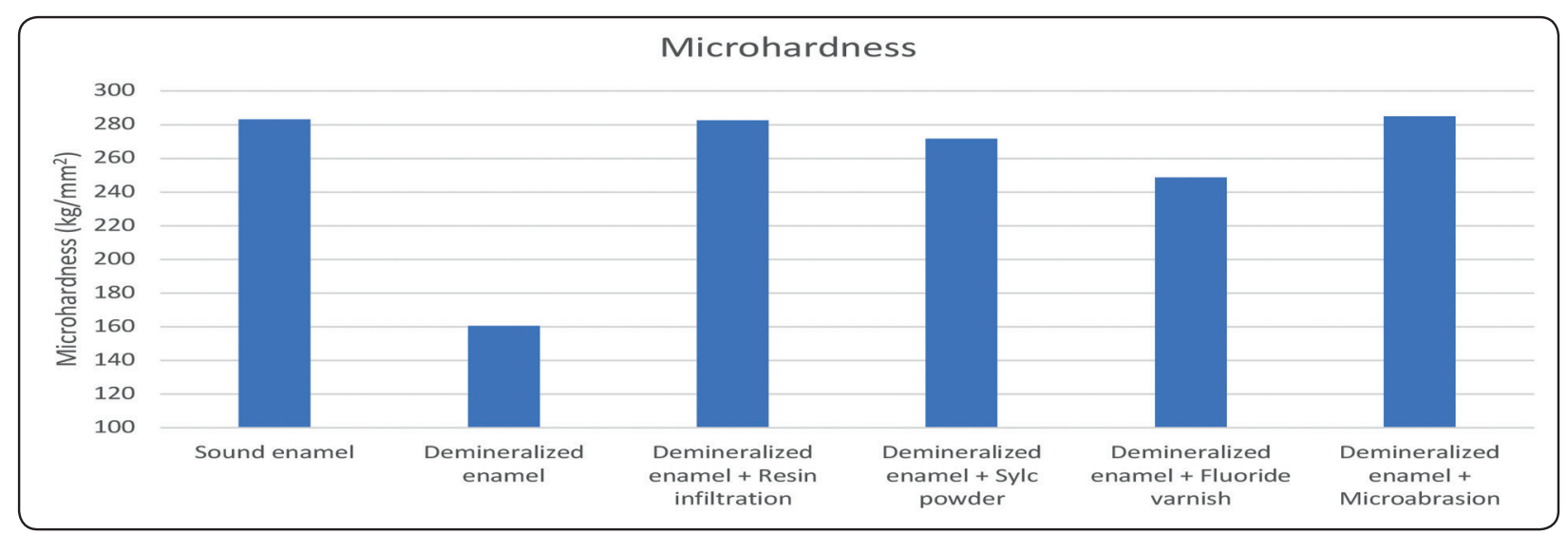

Fig. (1) Bar chart showing microhardness mean values of different study groups

\section{DISCUSSION}

The early visual appearance of dental caries in enamel is called 'white spot' lesion. It appears due to the change in the refractive index among the lesion's contents of air and electrolytes and the adjacent sound enamel. Initial enamel caries must be detected as early as possible to be treated by remineralization and to cease the progression of the lesions ${ }^{(17)}$. Nowadays, noninvasive and micro invasive treatment modalities were introduced either to arrest lesion progression or to remineralize the lesion as resin infiltration (Icon) and remineralizing gents as fluoride and bioactive-glass powder ${ }^{(18)}$. Resin infiltration technique arrests the progression of the initial caries by filling the porosities of the lesion subsurface using a light- cured low viscosity liquid called resin infiltrants ${ }^{(19-21)}$. Microabrasion is another microinvasive treatment of incipient enamel lesions ${ }^{(22-24)}$. The technique aims to treat superficial enamel lesions by removing the outermost layers of enamel by mechanical abrasion. The concurrent chemical erosion creates a smooth and lustrous surface ${ }^{(23,25)}$. This treatment approach was 
encouraged for treatment of white spot lesions after orthodontics ${ }^{(22,23)}$. Combination of acidic and abrasive compounds was applied to the demineralized enamel surface as microinvasive treatment ${ }^{(23,24,26)}$. Moreover, Sylc poweder is a therapeutic powder that is composed of $100 \%$ Novamin bioactive glass used as air abrasion polishing system that reminieralizing potential for the demineralized enamel and dentin $^{(27)}$.

Hardness of enamel is considered a crucial mechanical property that reflects its resistance against indentation or penetration. Thus, it influences the resistance of this outermost protective layer to all lesions that might affect the tooth as abrasion, erosion, attrition or even dental caries. This means that the higher levels of mineral content in enamel; the lower levels of enamel loss due to theses lesions (28) . Therefore, in this study, micro hardness values for all specimens were measured in 3 steps; the base line micro hardness, after demineralization and after treatment. In view of the relationship between mineral content and surface micro-hardness of enamel, the latter can be used as a measure to evaluate the efficacy of different treatment modalities in stopping the demineralization process. Accordingly, similar to previous studies ${ }^{(10,15)}$ the mean surface micro-hardness of all samples at baseline and after demineralization was about 283.28 and 160.49 VHN, respectively. Moreover, although primary lesions of enamel manifested an intact surface, their mineral content, and thus micro-hardness, was decreased in comparison to an sound enamel. So, the aim of this study was to evaluate effect of different treatment modalities including noninvasive and microinvasive treatments on microhardness of enamel surface. Therefore, in the current study, the micro hardness values for each specimen were measured in three stages; the base line micro hardness for sound enamel, after demineralization and after treatment. Results of this study showed that there was a statistically significant difference in $\mathrm{MH}$ values between the different groups. So, the null hypothesis was rejected as the different treatment modalities of white spot lesions did affect the microhardness of human enamel.

In this study the highest microhardness mean was for the microabrasion group, this could be attributed by total removal of the demineralized layer of the lesion by the chemical action of hydrochloric acid augmented by mechanical action of the abrasive pumice particles; exposing sound enamel layer with high micrhardness ${ }^{(24)}$.In addition, the acid compound of microabrasion slurry might change prismatic structure of enamel, obtaining a compacting effect on enamel surface with consequent higher enamel microhardness ${ }^{(29,30)}$.

Regarding the resin infiltration results that was insignificant with the microabrasion ones, it is well known that incipient lesions are composed of microscopic pores within the defect body, while the lesion surface remains relatively intact (pseudointact surface layer). This could prevent proper penetration of flowable resin into the lesion. That is why the pseudointact surface layer was removed by chemical etch with powerful hydrochloric acid before resin infiltration ${ }^{(31,32,33)}$. The main objective of the resin infiltration technique was not total removal of the surface layer, but rather, to improve the penetration ability of the low-viscosity resins into the inner pores of the lesion body. This penetration of the infiltrant protects the lesion from further acid attacks. Additionally, following curing of the resin material inside the lesion, progression of the lesion might be arrested and mechanical strengthening of enamel surface might be achieved ${ }^{(31,34,35)}$. These results for microabrasion and resin infiltration were in agreements with many other studies $(29,30,31,34,35,36,37)$.

Concerning the effect of Sylc powder on the microhardness of enamel, it showed significant improvement in microhardness more than that of fluoride application. This might be due to the calcium sodium phosphosilicate bioactive glass that was gradually substituted by hydrogen ions. Consequently, a thick layer fully saturated with calcium and phosphate precipitates on the tooth 
surface was formed with an increase of environment $\mathrm{pH}$ preventing the demineralization process and substitute the lost minerals of the demineralized enamel $^{(38,40)}$.Nano-particles of calcium and phosphate have high infiltration capacity into the demineralized subsurface by air abrasion for 10 seconds that might remove the pseudo-intact surface to expose the lesion body creating a source of calcium and phosphate ions that subpress the demineralization process and enhance remineralization with subsequent increased microhardness ${ }^{(40)}$. Oppositely, after fluoride application to demineralized enamel, it forms hydroxyapatite fluoride, which is more resistant to acidic attacks than non-fluoridated hydroxyapatite ${ }^{(41)}$. However, the main effect of fluoride application on the demineralized enamel surface is the precipitation of globules of calcium fluoride $\left(\mathrm{CaF}_{2}\right)$, known as phosphate-contaminated calcium fluoride.

Despite of that fluoride varnish has higher fluoride concentration (22600 ppm), it was suspected that fluoride varnish improves the microhardness of enamel surface due to high concentrations of fluoride and its potential to decrease enamel dissolution in acid. This could be attributed to decreased contact time of the varnish with enamel surface in our study because fluoride varnish can react chemically with enamel through the first twenty four hours. One-time application of fluoride varnish was done to simulate professional clinical condition with referring to the artificial saliva to act as source of the remineralizing agents similar to real situations ${ }^{(42)}$. These results are consistent with the studies of Lata et al. ${ }^{(15)}$, Esfahani et al. ${ }^{(43)}$, Shetty et al. ${ }^{(45)}$ and Vysal et al. ${ }^{(46)}$

\section{CONCLUSIONS}

The findings of our study revealed that, concerning the tested treatment modalities, microabrasion, resin infiltration approach as well as bioactive glass air polishing system improved enamel surface microhardness in comparison to fluoride varnish. It is recommended that more in-vivo studies should be conducted on impact of these treatment modalities intra-orally.

\section{REFERENCES}

1. Silverstone LM. Structural alterations of human dental enamel during incipient carious lesion development. In: Rowe N (ed). Proceedings of symposium on incipient caries of enamel. November 11-12, 1977, the University of Michigan, School of Dentistry, Ann Arbor, MI: University of Michigan School of Dentistry; 1977. pp. 3-42.

2. Doméjean S, Ducamp R, Léger S, Holmgren C. Resin infiltration of non-cavitated caries lesions: a systematic review. Med Princ Pract. 2015;24(3):216-221.

3. Kidd EA, Fejerskov O. What constitutes dental caries? Histopathology of carious enamel and dentin related to the action of cariogenic biofilms. J Dent Res. 2004; 83:35-38.

4. Chau NP, Pandit S, Jung JE, Jeon JG. Evaluation of streptococcus mutans adhesion to fluoride varnishes and subsequent change in biofilm accumulation and acidogenicity. $\mathrm{J}$ Dent. 2014; 42(6): 726-734.

5. Soley A, Orcun Y, Atalay M, Suat OC, Sezer DB. Effect of resin infiltration on enamel surface properties and streptococcus mutans adhesion to artificial enamel lesions. Dent Mater J. 2015; 34(1): 25-30.

6. Torres CR, Rosa PC, Ferreir NS, Borges AB. Effect of caries infiltration technique and fluoride therapy on microhardness of enamel carious lesion. Oper Dent. 2012; 37(4): 363-369.

7. Kielbassa AM, Ulrich I, Treven L, et al. An updated review on the resin infiltration technique on incipient proximal enamel lesions. Med Evol. 2010;16:3-15.

8. Kielbassa AM, Muller J, Gernhardt CR. Closing the gap between oral hygiene and minimally invasive dentistry: a review on the resin infiltration technique of incipient (proximal) enamel lesions. Quintessence Int. 2009;40:663-681.

9. Paris S, Meyer-Lueckel H, Kielbassa AM. Resin infiltration of natural caries lesions. J Dent Res. 2007;86:662-666.

10. Paris S, Schwendicke F, Seddig S, et al. Micro-hardness and mineral loss of enamel lesions after infiltration with various resins: influence of infiltrant composition and application frequency in vitro. J Dent. 2013;41:543-548.

11. Pini NI, Sundfeld-Neto D, Aguiar FH, et al. Enamel microabrasion: an overview of clinical and scientific considerations. World Journal Clin Cases. 2015;3:34-41.

12. Donly KJ, O'neill M, Croll TP. Enamel microabrasion: a microscopic evaluation of the 'abrosion effect'. Quintessence Int. 1992;23: 175-179. 
13. Golpayegani MV, Sohrabi A, Biria M, Ansari G. Remineralization Effect of Topical NovaMin Versus Sodium Fluoride $(1.1 \%)$ on Caries-Like Lesions in Permanent Teeth. J Dent (Tehran). 2012 ;9(1):68-75.

14. Roy S \& Basu B. Mechanical and tribological characterization of human tooth. Mater Charact. 2008; 59: 747-56.

15. Lata S, Varghese NO, Varughese JM. Remineralization potential of fluoride and amorphous calcium phosphatecasein phospho peptide on enamel lesions: An in vitro comparative evaluation. J conserv dent. 2010; 13(1): 42-46

16. Ayam AT, Robert GH , Padhraig SF, Mangala PP. Development of a novel bioactive glass for air-abrasion to selectively remove orthodontic adhesives. Clinic oral invest. 2018;22:1839-1849

17. Hammad S, El Banna M, El Zayat I, Mohsen M. Effect of resin infiltration on white spot lesions after debonding orthodontic brackets. Am J Dent. 2012; 25: 3-8.

18. Kielbassa A, Muller J, Gernhardt C. Closing the gap between oral hygiene and minimally invasive dentistry: a review on the resin infiltration technique of incipient (proximal) enamel lesions. Quintessence Int. 2009; 40: 663-8.

19. Paris S, Meyer LH. Infiltrants inhibit progression of natural caries lesions in vitro. J Dent Res. 2010; 89:1276- 80.

20. Mahdiye A, Homayoon A, Zahraa S, Nilgoon P, Ali B, Abdolreza E, Zohre D. Comparison of the effect of resin infiltrant, fluoride varnish and nanohydroxy apatite paste on surface hardness and streptococcus mutans to artificial enamel lesions. Electro Physi. 2017; 9(3): 3934-3942

21. Paris S, Meyer-Lueckel H, Kielbassa AM. Resin infiltration of natural caries lesions. J Dent Res. 2007; 86: 662-666.

22. Ardu S, Castioni NV, Benbachir N, et al. Minimally invasive treatment of white spot enamel lesions. Quintessence Int. 2007; 38:633-636

23. Murphy TC, Willmot DR, Rodd HD. Management of postorthodontic demineralized white lesions with microabrasion: a quantitative assessment. Am J Orthod Dentofacial Orthop. 2007;131:27-33.

24. Pini NI, Sundfeld-Neto D, Aguiar FH, et al. Enamel microabrasion: an overview of clinical and scientific considerations. World Journal Clin Cases. 2015;3:34-41.

25. Donly KJ, O’neill M, Croll TP. Enamel microabrasion: a microscopic evaluation of the 'abrosion effect'. Quintessence Int. 1992;23: 175-179.
26. Lynch CD, Mcconnell RJ. The use of microabrasion to remove discolored enamel: a clinical report. J Prosthet Dent. 2003;90:417-419.

27. Mehta AB, Kumari V, Jose R, Izadikhah V. Remineralization potential of bioactive glass and casein phosphopeptide-amorphous calcium phosphate on initial carious lesion: An in-vitro pH-cycling study. J Conserv Dent. 2014;17(1):3-7

28. Soley A, Orcun Y, Atalay M, Suat OC, Sezer DB. Effect of resin infiltration on enamel surface properties and streptoccuse mutans adhesion to artificial enamel lesions. Dent Mater J. 2015; 34(1): 25-30.

29. Bertoldo CE, Pini NI, Miranda DA, et al. Physicochemical properties of enamel after microabrasion technique. J Res Dent. 2014; 2:176-188.

30. Fragoso LS, Lima DA, de Alexandre RS, et al. Evaluation of physical properties of enamel after microabrasion, polishing, and storage in artificial saliva. Biomed Mater. 2011;6:1-6.

31. Paris S, Meyer-Lueckel H, Kielbassa AM. Resin infiltration of natural caries lesions. J Dent Res. 2007;86:662-666.

32. Meyer-Lueckel H, Paris S, Kielbassa AM. Surface layer erosion of natural caries lesions with phosphoric and hydrochloric acid gels in preparation for resin infiltration. Caries Res. 2007;41:223-230.

33. Tostes MA, Santos E Jr, Camargo SA Jr. Effect of resin infiltration on the nanomechanical properties of demineralized bovine enamel. Indian J Dent. 2014;5:116-122.

34. Mueller J, Meyer-Lueckel H, Paris S, et al. Inhibition of lesion progression by the penetration of resins in vitro: influence of the application procedure. Oper Dent. 2006; 31:338-345.

35. Kielbassa AM, Ulrich I, Schmidl R, et al. Resin infiltration of deproteinised natural occlusal subsurface lesions improves initial quality of fissure sealing. Int J Oral Sci. 2017; 9:117-124.

36. Torres CRG, Rosa PCF, Ferreira NS, Borges AB. Effect of caries infiltration technique and fluoride therapy on microhardness of enamel carious lesions. Oper Dent. 2012; 37: 363-9.

37. Paris S, Schwendicke F, Seddig S, Müller WD, Dörfer C, Meyer-Lueckel H. Micro-hardness and mineral loss of enamel lesions after infiltration with various resins: Influence of infiltrant composition and application frequency in vitro. J Dent. 2013; 41: 543-8. 
38. Wang Z, Jiang T, Sauro S, Wang Y, Thompson I, Watson TF, Haapasalo M. Dentine remineralization induced by two bioactive glasses developed for air abrasion purposes. J dent. 2011;39(11): 746-756.

39. Ayam AT, Robert GH , Padhraig SF, Mangala PP. Development of a novel bioactive glass for air-abrasion to selectively remove orthodontic adhesives. Clinic oral invest. 2018;22:1839-1849

40. Hebatallah MT, Haridy MF. Effect Of Artificial Saliva, Bioactive Glass And Fluoride Varnish On Micro-Hardness And Micro -Shear Bond Strength Of Demineralized Enamel Surface. Egy Dent J. 2019: 65:471-481

41. Ten Cate JM, Duijsters PPE. Influence of fluoride in solution on tooth demineralization. Caries Res. 1983;17: 193-199.
42. Carvalho FG, Vieira BR, Santos RL, Carlo HL, Lopes PQ, Lima BA. In vitro effects of nano- hydroxyapatite paste on initial enamel carious lesions. Pediatr Dent. 2014; 36(3):85-9.

43. Salehzadeh Esfahani K, Mazaheri R, Pishevar L. Effect of Treatment with various remineralizating agents on the microhardness of demineralized enamel surface. J Dent Res Dent Clin Dent Prospects. 2015; 9(4): 239-245.

44. Shetty S, Hegde MN, Bopanna TP. Enamel remineralization assessment after treatment with three different remineralizing agents using surface microhardness: An in vitro study. J conseru Dent. 2014;17(1):49-52.

45. Vysal T, Amasyali M, koyuturk AE, Ozcen S. Effect of difference topical agent on enamel demineralizations around orthodentics brackets an in vivo and in vitro study. Aust Dent J. 2010; 55(3): 268-74. 